\title{
Inversión pública y crecimiento del turismo en el distrito de Santa María, 2015 - 2017
}

Public investment and tourism growth in the Santa María district, 2015 - 2017

José García Paredes', Jesús Jacobo Coronado Espinoza

\section{RESUMEN}

Objetivo: Describir la relación existente entre la inversión pública local y el crecimiento económico del turismo en el distrito de Santa María de la provincia de Huaura en los años 2015 al 2017. Método: Básico, descriptivo y transversal, con enfoque cuantitativo y no experimental; efectuado en una población y muestra conformada por 25; 27 y 22 proyectos de inversión pública distrital agrupados por sectores, correspondientes a los años 2015; 2016 y 2017, respectivamente. El instrumento para la toma de datos fue el análisis documental, reforzada con la observación. Resultados: La inversión pública local se orientó básicamente a la infraestructura social y económica. No se observó una inversión pública distrital orientada a promover el crecimiento económico del turismo que corresponda a un plan auténticamente articulado en todos los sectores económicos y sociales del distrito, al respecto, solo existen planes de nivel distrital y regional. Sin embargo, se puede estimar que dicha inversión efectuada de algún modo posibilitó el crecimiento económico desordenado de aproximadamente un $1 \%$ de la actividad turística mayormente en operadores con deficiencias en su calidad de servicio como los "restaurantes y servicios de hospedaje" gracias a la iniciativa propia de sus propietarios. Conclusión: Los hallazgos revelaron una escasa promoción de la inversión pública en el crecimiento económico del turismo en la zona de estudio, fundamentalmente en patrimonio cultural/natural, cultura y conciencia turística bajo un contexto competitivo que el mercado exige. No obstante, existe diversos recursos y posibilidades para potencializar el turismo.

Palabras clave: Inversión pública, crecimiento económico.

\section{ABSTRACT}

Objective: To describe the relationship between local public investment and the economic growth of tourism in the Santa María district of the Huaura province in the years 2015 to 2017. Method: Basic, descriptive and cross-sectional, with a quantitative and non-experimental approach; carried out in a population and sample made up of 25; 27 and 22 district public investment projects grouped by sectors, corresponding to the years 2015; 2016 and 2017, respectively. The instrument for data collection was documentary analysis, reinforced with observation. Results: Local public investment was basically oriented to social and economic infrastructure. No district public investment was observed to promote the economic growth of tourism that corresponds to a truly articulated plan in all the economic and social sectors of the district; in this regard, there are only district and regional level plans. However, it can be estimated that said investment somehow made possible the disorderly economic growth of approximately $1 \%$ of the tourist activity, mainly in operators with deficiencies in their quality of service such as "restaurants and lodging services" thanks to the initiative own of their owners. Conclusion: The findings revealed a poor promotion of public investment in the economic growth of tourism in the study area, mainly in cultural / natural heritage, culture and tourism awareness in a competitive context that the market demands. However, there are various resources and possibilities to enhance tourism.

Keywords: public investment and economic growth of tourism. 


\section{INTRODUCCIÓN}

En comparación con otros países, el turismo en nuestro país es una actividad económica relativamente joven, altamente generadora de puestos de trabajo a costos mucho más bajos que otros sectores económicos; pues, sin embargo, en la zona de estudio el turismo no está siendo adecuadamente atendido, en términos de promoción de la inversión, por parte de las autoridades correspondientes al sector público. Situación que en muchos casos se puede atribuir a la baja cultura y conciencia turística en la población y sus autoridades.

En dicho contexto, fundamentalmente el estado, a través de la inversión pública de sus instituciones de desarrollo pertinentes, en los tres niveles de gobierno: Nacional-regional-local, es el llamado a promover el crecimiento económico del turismo en el distrito motivo de investigación en concordancia con las normas de calidad y competitividad nacional e internacional. Para lo cual obviamente se requiere primeramente describir y caracterizar el destino de la inversión pública local asociada al crecimiento económico del turismo.

El distrito de Santa María es aún catalogado como pobre (Plan de Desarrollo Concertado del distrito Santa María 2011-2021-FONCODES), con una gran diversidad de necesidades, que la inversión pública local total en el período de estudio de S/.17 433293 fue insuficiente para atender los requerimientos de una población con más de 37 000 habitantes que se dedican básicamente a la agricultura y comercio, disponiendo, además, de una gran riqueza en patrimonio cultural y de diversos recursos turísticos con gran potencial de transformarse en producto turístico, motivo por el cual, el lento crecimiento del turismo viene siendo de manera desordenada y con predominio de notables deficiencias en la calidad de servicio de los operadores turísticos, principalmente en los restaurantes y servicio de hospedaje, entre otros, que son generadoras de empleo e ingresos de la comunidad.

Lambogglia (2014) en su investigación sobre el "análisis del turismo y su importancia en el crecimiento económico en América Latina: el caso del Ecuador", presenta un análisis del sector turístico y sus determinantes; y, como este sector influye en el crecimiento en la economía de los países latinoamericanos, haciendo énfasis en el estudio del caso Ecuatoriano mediante el cual se pretende resaltar la incidencia potencial que esta industria podría tener en el desarrollo y crecimiento económico del país.

Las investigaciones de Capanegra (2006), nos alcanza una visión resumida de las principales orientaciones del turismo como instrumento de política pública en cada uno de los diferentes modelos de acumulación que durante el siglo XX tuvieron lugar en Argentina.

Aguiló y Vichi (1996), en su trabajo, señalan que los cambios que han sufrido los estudios turísticos referidos al ámbito de la política económica aplicable al sector han estado precedidos por importantes transformaciones en las últimas cuatro décadas. En determinadas circunstancias el análisis se ha decantado por reforzar los objetivos planteados por acción del gobierno en materia turística y, en otras, se ha impuesto el planteamiento crítico junto con propuestas para acelerar los cambios previstos en el modelo imperante de turismo vacacional. También, indican que las primeras aportaciones de la política turística en el marco del primer gran "boom" turístico de los sesenta se realizan dentro de tratamientos de economía general en los que junto al turismo se estudian otros sectores. Señala, asimismo la incorporación de la oferta turística en España como estrategia de crecimiento económico considerado en los planes, objetivos y políticas desde los años 60 , promocionado por su respectivo gobierno y a nivel de gobiernos locales.

Barreto, Collantes, Garland y Rodríguez (2017), quienes en su investigación señalan que a nivel mundial el turismo crece en promedio el $7 \%$ y particularmente en Sudamérica al $8 \%$ a pesar de los constantes cambios macroeconómicos y problemas políticos. En el Perú, el turismo ha venido creciendo en forma constante aunque con cierta desaceleración en los últimos años debido a ineficiencias en la promoción e inactividad en el desarrollo de productos turísticos, llegando alrededor del $7 \%$, aún sin mucho esfuerzo. En el Plan Estratégico preparado para el Sector Turismo encontramos que el Perú, reconocido alrededor del globo por Machu Picchu (una de las siete maravillas del mundo) y por su gastronomía (capital gastronómica del mundo) tiene múltiples recursos turísticos inimitables. Sin haber logrado convertirse en líder receptor de turistas internacionales ni en la captación de sus divisas, siendo desplazado por países vecinos como Colombia y Chile.

El análisis del sector muestra una completa desarticulación de la gestión del turismo en el país, un manejo inadecuado de recursos turísticos que no han sido puestos en valor y una deficiente infraestructura de transporte y servicios básicos que podría hacer que el sector colapse en pocos años. El análisis FODA realizado ha permitido proponer estrategias enfocadas a mejorar la gestión del sector teniendo presente los intereses de los cuatro stakcholders: El Estado, la empresa privada, la población y el turista. En este sentido se han propuestos objetivos a fin de duplicar el número de turistas extranjeros en cinco años sobre 
la base de alternativas de modernización de la gestión del Estado mediante el uso de una organización de vanguardia que permita lograr objetivos mediante el empoderamiento de órganos transversales con gestión matricial sobre las estructuras sectoriales del gobierno. Se observa al sector turístico con optimismo, las entrevistas a especialistas del sector confirman que es posible lograr los objetivos, los competidores no pueden duplicar nuestros múltiples atractivos culturales, pero nosotros si podemos aprender de sus éxitos. Sus conclusiones: Para lograr un desarrollo del sector turismo del país se necesita concentrar todos los esfuerzos; de modo que se concrete la llegada de visitantes extranjeros de clase alta y media a siete millones al 2021 además de incrementarse el ingreso por turismo a más de 7700 millones de dólares estadounidenses. Para lo cual se requiere que el sector público y privado trabaje en forma alineada y articulada, sin una visión compartida, por todos ellos, el plan estratégico para el sector turismo será difícil de alcanzar. El éxito de este plan de reflejará en una ganancia para todos los stakcholders del sector se incrementará a 500000 el número de empleos directos del turismo para el 2021, lo que redundaría en mejores condiciones de vida para las personas, desarrollo sostenible de las comunidades y mayor competitividad a las empresas.

Fernández y Pacco (2016), en su investigación acerca del análisis de la inversión pública y su impacto en la economía de la provincia de Canchis, Cusco-Perú (2007-2013), entre sus conclusiones señala que es necesario que el gobierno provincial destaque en la asignación equitativa de los proyectos de inversión pública entre el sector tradicional y moderno de acuerdo a las características que cada uno de ellos posee, y se constata que la inversión pública y el crédito financiero tienen un efecto positivo sobre la productividad media, los cuales afectan de distinta manera; el crédito es la variable que incrementa en mayor proporción la productividad media del sector tradicional, en comparación al impacto de la inversión pública sobre la productividad de este sector, demostrando así que la inversión pública y el crédito financiero son necesarios para impulsar el crecimiento económico a través de la productividad media.

Ponce (2013), en su investigación sobre la inversión pública y desarrollo económico regional, se observa que a pesar del crecimiento de la inversión pública durante los últimos años, existen algunas deficiencias que tendrían que ser superadas. Por ello, es relevante identificar la inversión productiva, como aquella que genera no solo crecimiento económico sino también que genera mayor rentabilidad social, con el fin de lograr la convergencia regional. Es decir, se pretende demostrar que el dinamismo de la inversión pública contribuye al crecimiento económico, no obstante, aún persisten disparidades regionales que deben ser superadas.

Las bases teóricas, según referencias bibliográficas, coinciden al sostener que la inversión es el motor de crecimiento económico en toda sociedad. Aspecto de vital importancia cuando tienen que considerar un destino de la inversión en función a una estrategia de crecimiento económico debidamente articulado en sus sectores económicos y sociales estratégicos de acuerdo a la disponibilidad de recursos de la zona bajo investigación.

Es de destacar los aportes de diversos autores que el turismo no solo promueve los niveles de empleo a bajo costo, también es generadora de divisas, su interacción con los demás sectores económicos y sociales genera mayores oportunidades de crecimiento económico.

Por tal motivo, el presente estudio tuvo como objetivo describir la relación entre la promoción de la inversión pública y el crecimiento económico del turismo en el distrito de Santa María, período 2015-2017.

\section{MATERIAL Y MÉTODOS}

El tipo y diseño de investigación fue básica, no experimental y transversal; con enfoque cuantitativo. En razón al destino de la inversión pública local, el área geográfica de investigación comprendió el distrito de Santa María de la provincia de Huaura-Región Lima.

La población y muestra estuvo conformada por el total del número de proyectos de inversión pública del gobierno local ejecutados en el distrito indicado durante los años 2015; 2016 y 2017, dichos proyectos de forma agrupada se indican en la Tabla 1.

Tabla 1.

Población y muestra

\begin{tabular}{cccc} 
Población & \multicolumn{3}{c}{ Años } \\
\cline { 2 - 4 } y muestra & 2015 & 2016 & 2017 \\
\hline $\begin{array}{c}\text { Población } \\
\left(N^{\circ} \text { Proyectos }\right)\end{array}$ & 25 & 27 & 22 \\
\hline $\begin{array}{c}\text { Muestra } \\
\text { (No Proyectos })\end{array}$ & 25 & 27 & 22 \\
\hline
\end{tabular}


El método para la obtención de la población y muestra fue realizado a través de la revisión de fuentes documentales y electrónicos de las entidades públicas.

En el análisis estadístico se usaron técnicas estadísticas de procesamiento y análisis de datos tales como Tablas de frecuencia, participación y variaciones porcentuales, utilizando el Excel.

\section{RESULTADOS}

La insuficiente inversión pública diseminada en el ámbito distrital no registra una incidencia relevante en el crecimiento económico del turismo. El impacto de la inversión pública distrital sobre el crecimiento económico del turismo se estima aproximadamente en un $1 \%$ en el periodo de estudio, menor al crecimiento poblacional distrital del $2,5 \%$ anual.

La inversión pública local distrital fue fundamentalmente destinada a la infraestructura social, notándose una escasez de dicha inversión en conservación y aprovechamiento del patrimonio cultural y natural, inventario turístico, así como en capacitación sobre cultura y conciencia turística. Aspecto que coexistió con un descuido en tal aspecto. Lo mencionado, se muestra en la Tabla 2.

Tabla 2. Inversión pública en el distrito de Santa María, período 2015-2017

\begin{tabular}{lccc}
\multicolumn{1}{c}{ Destino de Inversión } & \multicolumn{3}{c}{ Años } \\
\cline { 2 - 4 } & 2015 & 2016 & 2017 \\
\hline Fortalecimiento Institucional & 0,004 & 0,19 & - \\
\hline Estudios de pre inversión & 13,7 & 2,11 & 2,09 \\
\hline Agua potable y alcantarillado & 18,9 & 22,95 & 30,33 \\
\hline Electrificación & 0,11 & - & - \\
\hline Seguridad Ciudadana & 6,10 & - & 0,21 \\
\hline Agricultura (Irrigación) & 0,51 & 0,13 & - \\
\hline Infraestructura Vial & 13,58 & 65,16 & 66,89 \\
\hline Señalización & 0,22 & - & - \\
\hline Salud & 0,0067 & - & - \\
\hline Decreto y recreación & 0,90 & 4,47 & 0,20 \\
\hline Muro de contención & 6,23 & - & - \\
\hline Educación (incluye infraestructura) & 30,61 & 2,66 & 0,38 \\
\hline Otros (Plazuelas y canalización de calles) & 9,03 & 2,33 & - \\
\hline Total & 100,0 & 100,0 & 100,0 \\
\hline Total en soles & 7618808 & 6758143 & 7056342 \\
\hline Ejecución presupuestal (\%) & 74,7 & 83,1 & 73,9 \\
\hline & & & - \\
\hline
\end{tabular}

Sin embargo, con fines de apoyar el turismo cultural, se diò el Acuerdo de Consejo Municipal $\mathrm{N}^{\circ}$ 0115-2016/MDSM (16-12-1016), que declara:

- Día nacional de la pachamanca, el primer domingo del mes de febrero de cada año.

- Festival de la vendimia, último sábado y domingo del mes de abril de cada año.

- Feria gastronómica de Luriama, en fiestas patrias de cada año.

- Festival del pato, último sábado y domingo del mes de setiembre de cada año. 
- Semana turística y cultural del distrito de Santa María, primera semana del mes de diciembre de cada año.

Los ingresos generados por dichas festividades no necesariamente se revierten para mejorar la calidad de servicio de los operadores participantes.

La zona turística del distrito está sustentada básicamente por su gastronomía en los restaurantes campestres, donde la demanda turística procede de las zonas urbanas de la provincia de Huaura. Actividad que requiere mayor atención en términos de calidad.

Asimismo, se ejecutó el proyecto denominado "Acondicionamiento de la ruta turística la Campiña", tomando como meta el acondicionamiento turístico de la laguna Encantada basado en el mejoramiento de la vía de acceso desde el cruce de la Av. Centenario hasta la laguna Encantada a nivel de afirmado. Dicha zona está deshabitada y carentes de servicios básicos, donde eventualmente se efectúan actividades gastronómicas y de entretenimiento en fechas festivas.

También, se observó muy ínfima ocurrencia de pequeñas ferias artesanales combinadas con venta de productos agrícolas, carentes de calidad.

El lento crecimiento de los operadores turísticos en el distrito es gracias a las iniciativas, capacidades emprendedoras, habilidades y riesgos de la propia población local.

\section{DISCUSIÓN}

A la fecha, en la zona de estudio los únicos estudios que se verifican son los relacionados a los planes estratégicos formulados por el Gobierno Regional de Lima. Plan de Desarrollo Regional Concertado 2016-2021 para el departamento de Lima y el Pan de Desarrollo Regional 2018-2021. A nivel distrital el Plan de Desarrollo Concertado al 2021.

Los resultados obtenidos en la presente investigación, coinciden con los hallazgos de Lombogglia (2014), en la medida que el turismo es una actividad importante en la generación de riqueza, tal como sucede en muchos otros lugares del país y en América Latina.

Por tal motivo es necesario que el turismo tenga un tratamiento especial como política de gobierno, lo que concuerda con los resultados de Capanegra (2006). Aspecto concordante con lo indicado por Aguiló y Vichi (1996), cuando concluye que es necesario mayor atención al turismo por parte de los gobiernos. También se coincide con los resultados de Barreto, Collantes,
Garland y Rodríguez (2017), cuando menciona que aún hay una desarticulación en la gestión del turismo, lo que permite formular estrategias de gestión considerando stakcholders: El estado, la empresa privada, la población y el turista, que requiere concentrar esfuerzos.

También se concuerda con las conclusiones de Fernández y Pacco (2014), cuando indica que es necesario asignar equitativamente la inversión pública según la realidad de los pueblos.

De modo específico, en la zona no existe un estudio técnico profesional especializado que establezca la influencia de la inversión pública en el crecimiento económico del turismo.

\section{AGRADECIMIENTOS}

Se agradece a los alumnos de la facultad de Ciencias Empresariales, operadores turísticos y población en general del distrito por su apoyo a la presente investigación.

\section{REFERENCIAS BIBLIOGRÁFICAS}

Aguiló, E. \& Vich I, G. Á. (1996): "La investigación en el ámbito de la política turística”. Instituto de Estudios Turísticos-Secretaría General de Turismo. España. Estudios Turísticos, (129), 23-35.

Barreto, S., Collantes, I., Garland, M. \& Rodríguez, E. (2017). Planeamiento estratégico para el sector turismo en el Perú. Tesis para optar el grado de Magister. Pontificia Universidad Católica del Perú. Lima, Perú.

Capanegra, Cesar Alejandro (2006). La política turística en la Argentina en el siglo XX. Aportes y Transferencias, 10(1), 43-61.

Fernández, J. C. \& Pacco, J. M. (2016). "Análisis de la inversión pública y su impacto en la economía de la provincia de Canchis, CuscoPerú (2007-2013)". Universidad Nacional de San Antonio Abad del Cusco, Cusco.

Lambogglia, J. (2014). "Análisis del turismo y su importancia en el crecimiento económico en américa latina: el caso del ecuador. Tesis para optar el título de Maestría. Facultad latinoamericana de ciencias sociales sede Ecuador". Flacso, Ecuador.

Ponce, S. (2013). Inversión Pública y Desarrollo Económico Regional. Tesis para optar el grado de Magister. Pontificia Universidad Católica del Perú. Lima, Perú.

Correo electrónico: jgarcia@unjfsc.edu.pe

Revisión de pares:

Recibido: 02/05/2019

Aceptado: 03/12/2019 